This is a pre-copyedited version of a contribution published in K. Jármai and B. Bolló (Eds.): Vehicle and Automotive Engineering 2 published by Springer International Publishing AG, part of Springer Nature. The definitive authenticated version is available online at: https://doi.org/10.1007/978-3-319-75677-6_13

\title{
Fatigue Performance of GMA-Brazed Non-Load Carrying Joints Made of Ultra-High Strength Steel
}

\author{
Antti Ahola, Tuomas Skriko, Timo Björk
}

Lappeenranta University of Technology, Lappeenranta 53851, Finland

\begin{abstract}
With the aim of maximizing energy efficiency, the use of low-alloyed ultra-high strength steels (UHSS) has greatly increased in vehicles and other transport applications in recent decades. Using UHSS, equivalent ultimate load capacity can be achieved with less material than when using conventional structural steels. Along with increased static load, structures commonly made of UHSS are often subjected to high cyclic load, and good fatigue strength is thus demanded. In this study, the fatigue strength was obtained for gas metal arc (GMA)-brazed non-load carrying joints made of S960 MC plates. CuMn13Al7 and $\mathrm{CuAl} 8$ were used as braze alloys. In addition, the work evaluated the potential of gas metal arc brazing (GMAB) as a post-weld improvement technique. A total of 21 different test specimens were manufactured and tested with constant amplitude fatigue tests with an applied stress ratio of $R=0.1$. Notch effects of the braze joints were investigated numerically using finite element analysis (FEA). Depending on the braze alloy and joint configuration, mean nominal fatigue strengths of FAT $\mathrm{T}_{\text {mean }}=134-192 \mathrm{MPa}$ were obtained, indicating that GMAB is a promising joining method for structures made of UHSS. The FEA results showed that for the studied materials and joints, stress concentration induced in the joint can decrease approximately by $20 \%$ when GMAB is applied instead of fusion welding.
\end{abstract}

Keywords: Fatigue strength, ultra-high strength steel, gas metal arc brazing, fatigue strength improvement

\section{Introduction}

Ultra-high strength steels (UHSSs) are increasingly being used in demanding applications such as aerial work platforms and other transport equipment where minimization of dead weight is essential for good energy efficiency. High static and fatigue strength is often required in such structures. Fusion welding is a common process for joining plates made of conventional steel grades. However, welding of low-alloyed UHSS causes additional requirements for manufacturing processes, since the high strength of the steel, which is obtained from precise thermo-mechanical treatment, might be lost if the base material is subjected to high heat input. As a result of high heat input, the cooling rate decreases and the cooling time $\left(t_{8 / 5}\right)$ simultaneously increases, which 
causes material softening in the heat affected zone (HAZ) and can thus drastically decrease the ultimate load capacity of a joint. It has been demonstrated that in non-load carrying joints such softening might result in the joint area being the weakest component of a structure [1].

GMAB (or MIG brazing) is a well-known process in industries where thin-walled structures are constructed using galvanized steel plates [2-5]. By using GMAB instead of conventional fusion welding, the beneficial effect of the galvanized layer, e.g. a zinc layer, on corrosion resistance is not lost, since the base material does not melt in the process. Potentially, GMAB can overcome the above-mentioned issues related to softening of UHSS. Furthermore, using carefully selected brazing parameters, smooth braze geometries, i.e. low flank angles and high toe radii, can be obtained, which contribute to achieving high fatigue strength. Moreover, GMAB is suitable for joining dissimilar materials $[6,7]$.

Mechanical properties, including fatigue strength, for GMA-brazed joints made of thin galvanized steel plates can be found in the literature [8-12], but less information is available for GMA-brazed joints made of thicker structural steels, since fusion welding is generally the more common joining process for such steels. The idea of utilization of GMAB as an fatigue improvement technique at LUT originated back to 1990's when replica Norton Manx frames were fabricated using Russian high strength steels in Estonia. In order to confirm the fatigue performance of those frames, GMAB was applied as a post-weld treatment method. However, the preliminary tests were carried out for joints made of conventional steels. Lepistö and Marquis [13] reported these results and identified GMAB as a potential joining process for structural steels in terms of fatigue strength. Recently, Gericke et al. [14] conducted tests for non-load carrying studs (S355) and reported similar findings concerning the potential applicability of GMAB. In their studies, the fatigue strength of the GMA-brazed studs was approximately $40 \%$ higher than the corresponding GMA-welded joints. In addition, Gericke et al. drew attention to the reduction in residual stresses and stress concentration factors (SCF) when GMAB is applied instead of welding. Despite these encouraging results, GMAB remains a novel joining method for thicker structural steels, and further investigations are thus needed. Furthermore, little attention has been paid to joints made of UHSS, which are the focus of this paper.

The work examines the fatigue performance of GMA-brazed joints made of UHSS. In the study, experimental fatigue tests of non-load carrying (NLC) joints were carried out and fatigue strengths at two million load cycles (FAT) obtained. Two types of specimens were under investigation: GMA-brazed NLC joints and GMA-welded NLC joints with an additional braze bead at the weld toe. Due to the lower elastic modulus of the braze alloy compared to the base material, a braze induces a lower SCF than a weld. Because brazing does not melt the base material, no initial cracks form at the toe area. Consequently, the nucleation period have a great impact on total fatigue life. Brazing with proper parameters enables having smooth transition in terms of toe radius and flank angle between the filler and base material thus decrease local stress concentration at braze toe. Due to the lower yield strength of the braze alloys compared to the matching steely filler materials, also residual stresses should be lower. These effects can have 
influence on fatigue strength by decreasing the efficiency of external loading or decreasing distortions of joint and thus secondary stresses. In addition, lower heat input decrease degree of softening in the UHSS, which can have an important effect on nucleation period in fatigue life. FEA was carried out to compare the SCFs of GMAbrazed and GMA-welded joints.

\section{Experimental Program}

\subsection{Materials}

This study investigates an ultra-high strength steel, S960 MC. Böhler Union X96 $(\mathrm{Mn} 4 \mathrm{Ni2} .5 \mathrm{CrMo}, \varnothing 1.0 \mathrm{~mm}$ ) was used as a matching filler material for the welded specimens and $\mathrm{CuAl}(\varnothing 1.0 \mathrm{~mm})$ and CuMn13Al7 $(\varnothing 1.2 \mathrm{~mm})$ as braze alloys for the GMAB. Chemical compositions and mechanical properties of the studied materials are presented in Table 1 and Table 2, respectively. As shown in Table 2, the yield and ultimate strength of CuMn13Al7 is very high compared to many other braze alloys. Consequently, high strength joints can be obtained using CuMn13Al7, although the alloy is an undermatching filler material for S960 MC. The strength properties of CuAl8 are substantially lower compared to the base material, but since its availability is generally good and this study focuses on non-load carrying joints where the strength of welds is not critical, $\mathrm{CuAl} 8$ was selected as a braze alloy.

Table 1. Chemical compositions of the studied materials (weight-\%).

\begin{tabular}{|c|c|c|c|c|c|c|c|c|c|}
\hline Material & $\begin{array}{l}\text { Type of } \\
\text { value }\end{array}$ & $\mathrm{C}$ & $\mathrm{Si}$ & $\mathrm{Mn}$ & $\mathrm{P}$ & S & $\mathrm{Al}$ & V & $\mathrm{Ti}$ \\
\hline S960 MC & maximum & 0.12 & 0.25 & 1.3 & 0.02 & 0.01 & 0.015 & 0.05 & 0.07 \\
\hline \multirow[t]{2}{*}{ S960 MC } & measured & 0.09 & 0.18 & 1.14 & 0.01 & 0.001 & 0.028 & 0.03 & 0.01 \\
\hline & & $\mathrm{C}$ & $\mathrm{Si}$ & Mn & $\mathrm{Cr}$ & Mo & $\mathrm{Ni}$ & & \\
\hline \multirow[t]{2}{*}{ Union X96 } & nominal & 0.12 & 0.8 & 1.9 & 0.45 & 0.55 & 2.35 & & \\
\hline & & $\mathrm{Mn}$ & $\mathrm{Al}$ & $\mathrm{Fe}$ & $\mathrm{Ni}$ & $\mathrm{Si}$ & & & \\
\hline $\mathrm{CuAl} 8$ & nominal & - & 7.8 & $<0.5$ & - & $<0.1$ & & & \\
\hline CuMn13Al7 & nominal & 13 & 7 & 2.5 & 2.5 & - & & & \\
\hline
\end{tabular}

Table 2. Mechanical properties of the studied materials.

\begin{tabular}{llrrrr}
\hline Material & $\begin{array}{l}\text { Type of } \\
\text { value }\end{array}$ & $\begin{array}{r}\text { Proof } \\
\text { strength } \\
R_{p 0.2}[\mathrm{MPa}]\end{array}$ & $\begin{array}{r}\text { Tensile } \\
\text { strength } \\
R_{m}[\mathrm{MPa}]\end{array}$ & $\begin{array}{r}\text { Elongation } \\
A_{5}[\%]\end{array}$ & $\begin{array}{r}\text { Impact } \\
\mathrm{KVC}[\mathrm{J}]\end{array}$ \\
\hline S960 MC & nominal & 960 & $980-1250$ & 7 & $27\left(-40^{\circ} \mathrm{C}\right)$ \\
S960 MC & measured & 1040 & 1140 & 10 & $83\left(-40^{\circ} \mathrm{C}\right)$ \\
Union X96 & nominal & 930 & 980 & 14 & $47\left(-50^{\circ} \mathrm{C}\right)$ \\
CuA18 & nominal & 175 & 420 & 40 & $70\left(+20^{\circ} \mathrm{C}\right)$ \\
CuMn13A17 & nominal & 650 & 900 & 10 & - \\
\hline
\end{tabular}




\subsection{Test Specimens}

NLC joints were fabricated from S960 MC plates with a thickness of $t=7.77 \mathrm{~mm}$. The main dimensions of the tested specimens are shown in Fig 1. Two different types of joint configuration were used. In the first two sets (Set 1 and Set 2), the joints were prepared using only GMAB with different braze alloys. In the third set (Set 3), the potential of GMAB as a post-weld improvement technique was under investigation, and a combination of gas metal arc welding (GMAW) and GMAB was applied. These joints were first prepared using GMAW and subsequently, additional beads were applied at the weld toes using GMAB, see Fig 1. A total of 21 specimens were fabricated and tested.

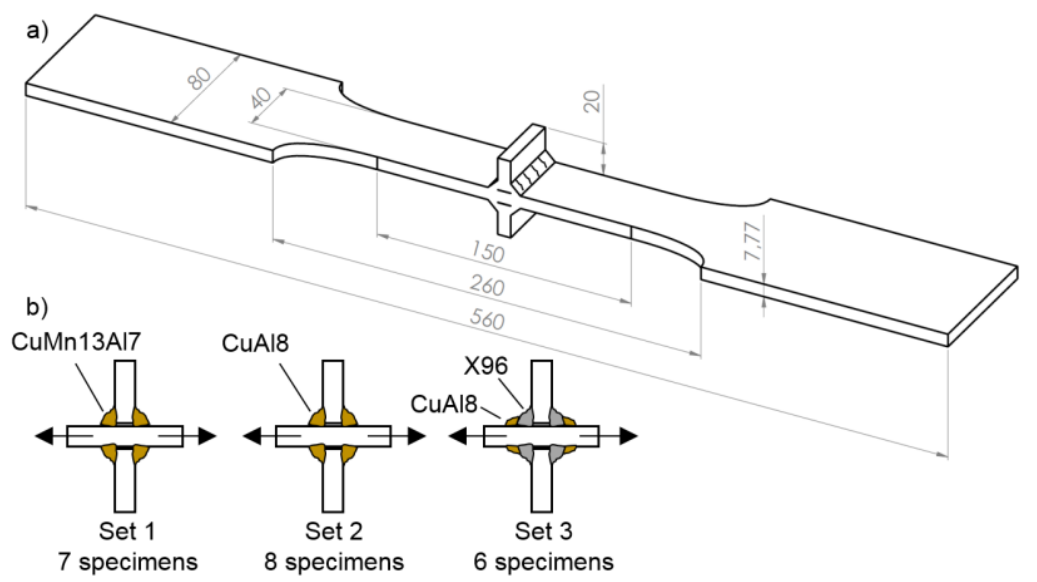

Fig. 1. Test specimens: (a) main dimensions of the specimens and (b) configuration for each set.

The preform of the specimens were laser-cut, and prior to GMA-processing, the plates were treated with citric acid $\left(\mathrm{C}_{6} \mathrm{H}_{8} \mathrm{O}_{7}\right)$ to remove roll scale and impurities from the plate surfaces. The specimens were prepared using mechanized single-pass welding or brazing, and a pulsed arc method was applied in the brazing process. The main parameters of the brazing and welding are presented in Table 3 . Beads were manufactured one pass at a time, and the specimens were allowed to cool down between the passes. Run-on and run-off parts of the specimens were subsequently sawed and machined, and the edges and corners of the specimens were ground to avoid fatigue failures starting from the edges of the sheet.

After manufacturing of Set 1, it was concluded on the basis of the braze shape measurements that the brazing parameters were not optimal for high quality geometries in terms of fatigue strength. With a low travel speed, the temperature of the specimen during brazing could not be controlled effectively, which had an unbalancing influence on molten braze behavior during the process. Consequently, with Set 2, a preheat temperature of $T_{p}=80^{\circ} \mathrm{C}$ was applied and travel speed was increased considerably in order to obtain better quality, see Table 3 . Heat inputs $(Q)$ were calculated using the following equation: 


$$
Q=\frac{\eta U I}{v}
$$

where $\eta$ is thermal efficiency ( 0.80 is assumed for the applied processes), $U$ is voltage, $I$ is current, $v$ is travel speed [15].

Table 3. Brazing and welding parameters. For GMAB, shielding gas was Ar and for GMAW, $\mathrm{Ar}+8 \% \mathrm{CO}_{2}$, respectively.

\begin{tabular}{|c|c|c|c|c|c|c|}
\hline Set & Process & $\begin{array}{r}\text { Current } \\
\mathrm{I}[\mathrm{A}]\end{array}$ & $\begin{array}{r}\text { Voltage } \\
\text { U [V] }\end{array}$ & $\begin{array}{r}\text { Wire feed } \\
\text { rate } \\
v_{\text {wire }}[\mathrm{m} / \mathrm{min}] \\
\end{array}$ & $\begin{array}{r}\text { Travel } \\
\text { speed } \\
v[\mathrm{~cm} / \mathrm{min}] \\
\end{array}$ & $\begin{array}{l}\text { Heat input } \\
Q[\mathrm{~kJ} / \mathrm{mm}]\end{array}$ \\
\hline 1 & GMAB & $195-205$ & 25 & 8.0 & 35 & 0.70 \\
\hline 2 & GMAB & $255-260$ & 27 & 11.5 & 100 & 0.34 \\
\hline 2 & GMAW & $240-250$ & 26.6 & 10.5 & 48 & 0.67 \\
\hline 3 & GMAB & $170-175$ & 23.5 & 8.0 & 100 & 0.20 \\
\hline
\end{tabular}

Before testing, hardness and residual stress measurements were carried out in selected specimens, Fig. 2. Residual normal stresses parallel to loading were measured at the weld toes in the centerline of specimen (four specimens per set and four measurements per specimen) using an X-ray diffractometer (Stresstech Xstress 3000 G3). The results indicated that the lowest (and even compressive) residual stresses were measured in Set 2, whereas in Set 1 and Set 3, the residual stress was tension at the braze toe.

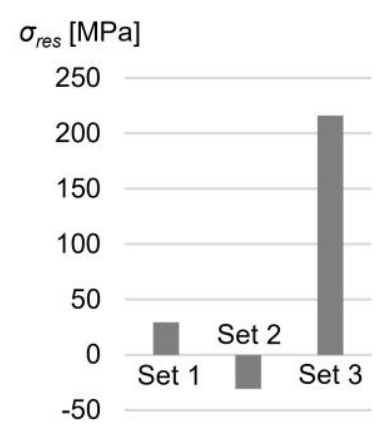

a)
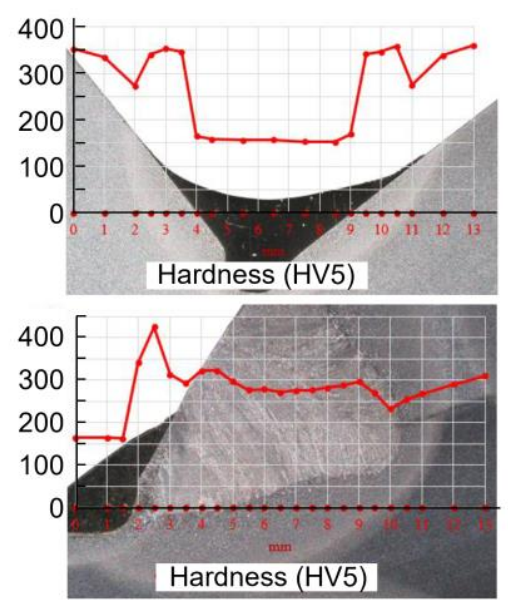

Fig. 2. Measurement results: (a) average of residual stress at the braze in each set and (b) hardness distributions in Set 2 and Set 3. 


\subsection{Test Set-Up}

Fatigue tests were performed using constant amplitude axial tensile loading with an applied stress ratio of $R=0.1$. Force was produced using a servo hydraulic actuator, Fig. 3a, and the minimum and maximum of applied load and displacement were measured during test. Due to the symmetric shape of the specimens and the low heat input, no significant angular distortions were found in the specimens, and consequently, the loading was mainly membrane stress. Nevertheless, each specimen was instrumented with a strain gage, Fig. 3b, located at $0.4 t$ distance $(3.1 \mathrm{~mm})$ from the weld toe to obtain secondary bending stress induced by angular distortion. Failure criterion for the end of the tests was total rupture of the specimen.

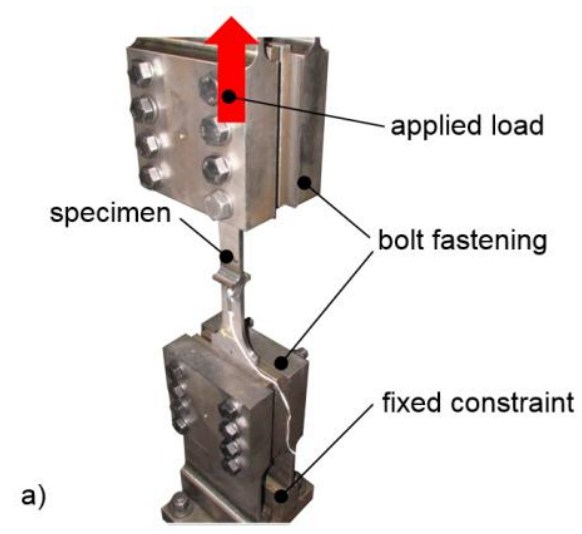

b)

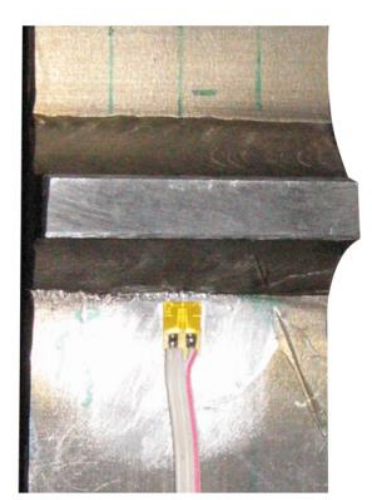

Fig. 3. Fatigue test set-up: (a) test rig and (b) strain gage instrumentation.

\subsection{Results}

Mean fatigue strength of each set was obtained using the standard procedure of linear regression in the following equation:

$$
\log N_{f}=\log C-m \cdot \log \Delta \sigma_{\text {nom }},
$$

where $N_{f}$ is fatigue life in cycles (dependent variable), $C$ is fatigue capacity, $m$ is the slope of the $S$ - $N$ curve, and $\Delta \sigma_{\text {nom }}$ is nominal stress range (independent variable). Due to the relatively low number of test specimens and the applied stress levels, a fixed slope of $S$ - $N$ curve, i.e. $m=3$, was applied following the IIW Recommendations [16]. Fatigue test data are plotted in Fig. 4 with the evaluated $S$ - $N$ curves. The computational mean fatigue strength (50\% survival probability) given by the IIW Recommendations can be derived from the characteristic design curve (mean minus two standard deviation, $97.7 \%$ survival probability) using a safety factor of $j_{\sigma}=1.37$, resulting in $\mathrm{FAT}_{\text {IIW,mean }}=110 \mathrm{MPa}$ [17]. 


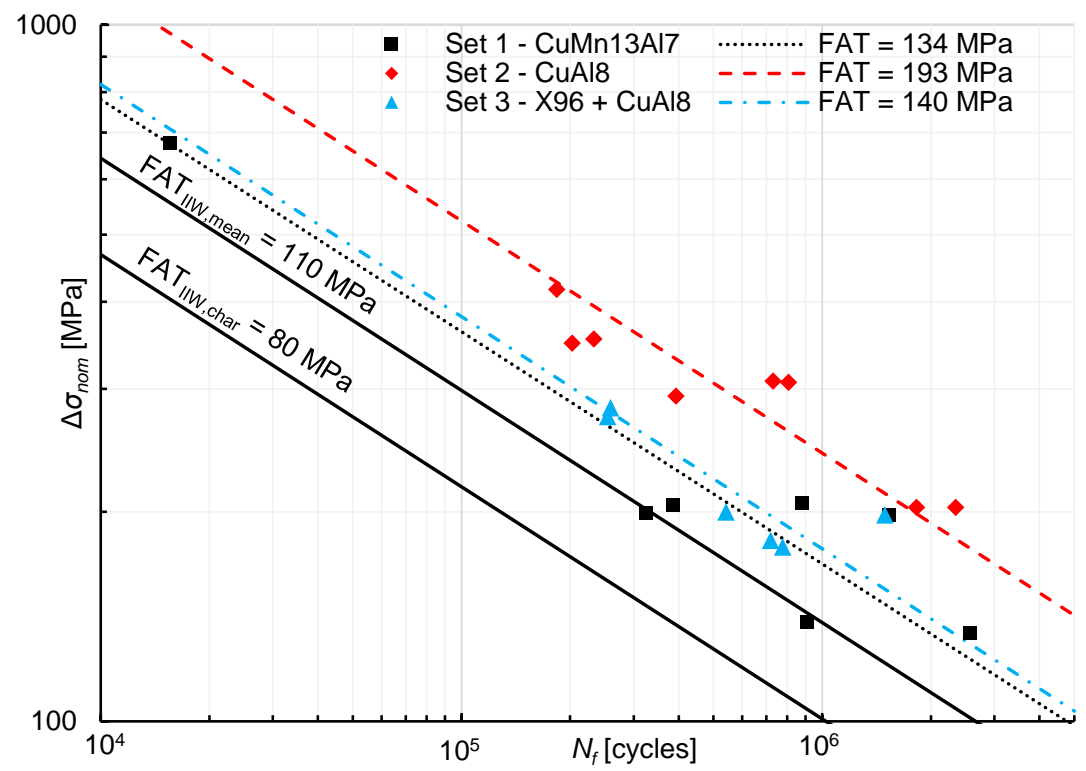

Fig. 4. Fatigue test data in the nominal stress system.

Based on the strain gage measurements and the measured shape of the specimens, no significant angular misalignments were found in the GMA-brazed specimens (Set 1 and Set 2), i.e. $K_{m}=1.0-1.05$. Consequently, the results obtained with the structural stress approach correspond to the results in terms of the nominal stress system. However, in Set 3, where fusion welding was used, the angular misalignments were slightly higher $\left(K_{m}=1.0-1.17\right)$, although the heat input was symmetric. For Set 3, the mean fatigue strength of the structural stress system was $\operatorname{FAT}_{\mathrm{hs}, \text { mean }}=151 \mathrm{MPa}(m=3)$.

\section{$3 \quad$ Finite Element Analysis}

FEA was carried out to investigate decrease in SCF when GMAB is applied instead of GMAW. All analyses were carried out using Femap with NxNastran (Siemens PLM Software) and two-dimensional parabolic plane strain element models. For the steel materials (S960 MC and Union X96), Young's modulus $E=210 \mathrm{GPa}$ and Poisson's ratio $v=0.3$ was used, and for the CuAl-based braze alloys, $E=120 \mathrm{GPa}$ and $v=0.3$, respectively. A quarter model with symmetry constraints and seed load of $1 \mathrm{MPa}$ were applied. The geometry, load and boundary conditions of the models are presented in Fig. 5.

Weld and braze toe radius of $r=1 \mathrm{~mm}$ was applied in accordance with effect notch stress (ENS) concept [18]. Due to the severe transition between the base material and braze alloy, regular-shaped quadrilateral elements, as presented e.g. in [19, 20], could not be applied at the toe radius. However, to obtain reliable results, the mesh size was decreased to $r / 40=0.025 \mathrm{~mm}$, which is one tenth of the recommended maximum size, 
i.e. $r / 4=0.25 \mathrm{~mm}$ for elements with quadratic order according to IIW [16]. To retain comparability of the different models, similar braze and weld geometry to the GMAbrazed and GMA-welded joints was chosen for the FE-model of the combination joint, although the analyzed geometry differs slightly from the combination joints tested experimentally, as shown later in Fig. 8 (Section 4).

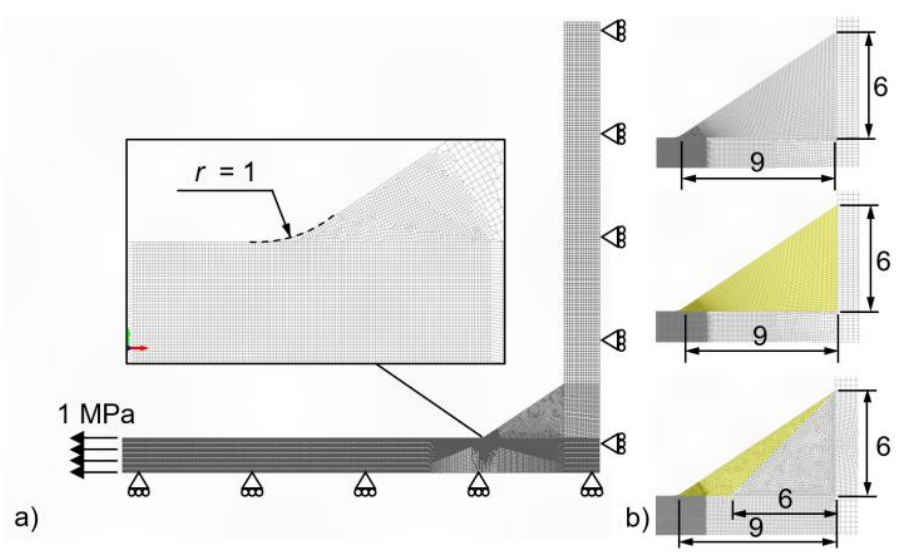

Fig. 5. FE models: (a) load and boundary conditions and (b) analyzed joint configurations.

Fig. 6 shows that SCF of the NLC X-joint decreases 23\% when brazing is used instead of welding. In the combination joint, a small additional braze bead shifts the maximum stress concentration location from the weld toe to the braze toe. In the combination joint, SCF is slightly higher than in the solely GMA-brazed joint but the reduction with respect to the welded joint remains significant.
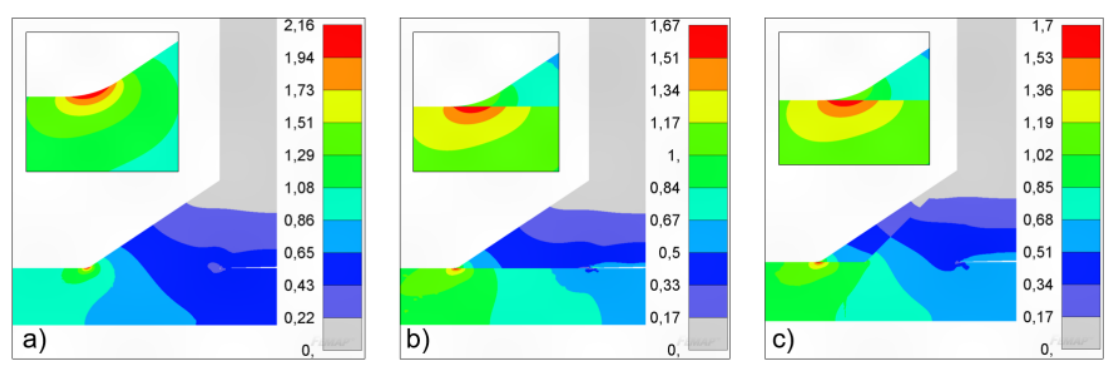

Fig. 6. SCFs in terms of maximum principal stress criterion for (a) welded, (b) brazed and (c) combination joint.

\section{Discussion}

Experimental fatigue tests were conducted for GMA-brazed NLC joints made of UHSS. The fatigue test results showed that the mean fatigue strength of the IIW Recommen- 
dations is exceeded in all sets. Generally, various materials and weld quality are covered in $S-N$ curves of codes and guidelines and consequently it is more reasonable to compare obtained results with similar welded NLC X-joints. Available fatigue data of GMA-welded joints made of S960 MC originally reported in [21-23] were selected for comparison. The tests in [21-23] were carried out for normal quality welds, i.e. weld toe radius $r<1 \mathrm{~mm}$ and without post-weld treatment. The specimens were prepared using either mechanized or robotic welding, and both matching (X96) and undermatching (OK AristoRod 12.50, $f_{y}=470 \mathrm{MPa}$ ) filler materials were used.

For the selected GMA-welded specimens, the mean fatigue strength is $\mathrm{FAT}_{\text {mean }}=$ $110 \mathrm{MPa}(m=3)$, using Eq. (2), and thus the $S$ - $N$ curve converges with the computational mean $S$ - $N$ curve of the IIW Recommendations. The fatigue test data of the GMAwelded specimens in [21-23] are plotted with the test results of this study in Fig. 7. It can be seen that the worst test results of the GMA-brazed joints (Set 1, black squares in Fig. 7) fall into the same $S-N$ curve as the GMA-welded specimens. Nevertheless, the mean fatigue strength of these GMA-brazed joints is $22 \%$ higher than the GMAwelded joints. Differences in the braze geometry and braze quality in Set 1 most likely explain the variation in the test results. In Set 2, however, the improvement level is substantially higher, i.e. $75 \%$ with respect to the GMA-welded specimens. In Set 3, where a combination of GMAB and GMAW was used, the fatigue strength is $27 \%$ higher than with GMA-welded joints.

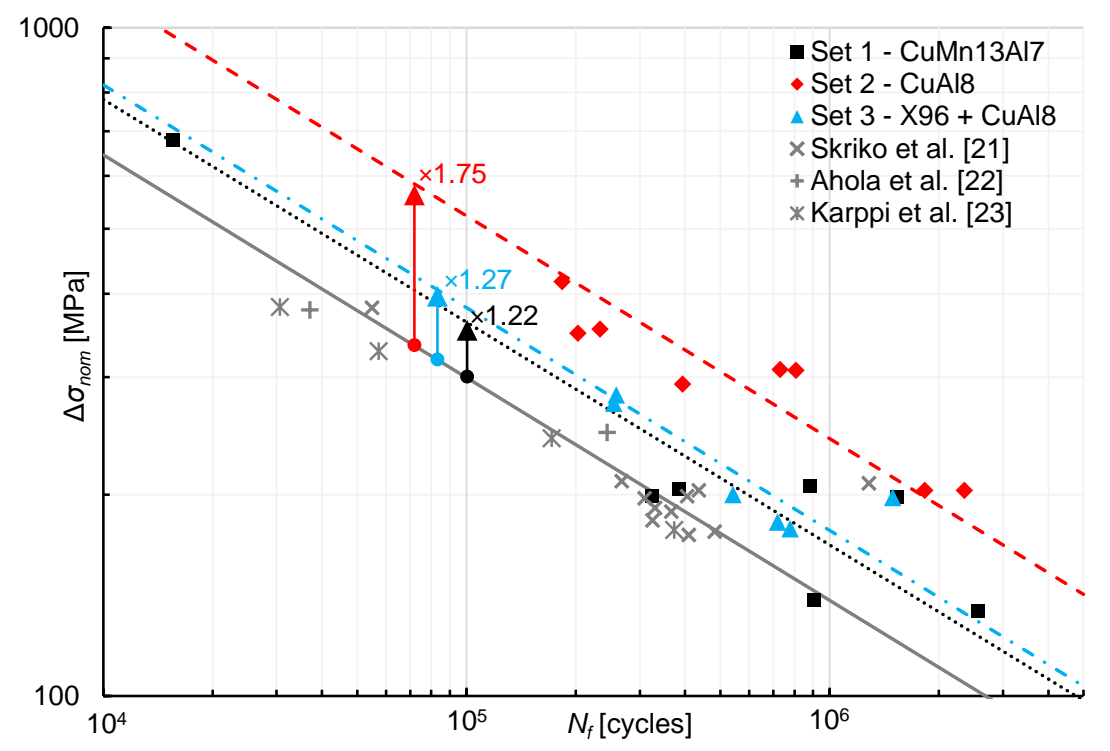

Fig. 7. Test results of this study in comparison with GMA-welded NLC joints made of S960 MC (normal quality, weld toe radius $r_{\text {toe }}<1 \mathrm{~mm}$ ) and tested in as-welded condition with constant amplitude loading $(R=0.1)$.

The discrepancy in fatigue strengths of Set 1 and Set 2 is a result of the different braze geometries. As discussed in Section 2.2, the fabrication of the specimens was 
slightly modified for Set 2, i.e. $T_{p}=80{ }^{\circ} \mathrm{C}$ preheat temperature was applied and travel speed was increased, which resulted in lower flank angles and higher toe radii than in Set 1 and Set 3, as shown in Fig. 8. On the basis of fabrication of the specimens, flowing ability of $\mathrm{CuAl} 8$ is higher than CuMn13A17 which contributed also achievement of good geometry in Set 2. In addition, the lowest residual stresses were measured in Set 2, Fig. 2; the lower residual stress promotes achievement of high fatigue strength. The highest tensile residual stresses were measured in the combination joints (Set 3), and although a moderate transition from base material to braze alloy was attained (see Fig. $8 \mathrm{c})$, the fatigue strength was not obviously higher than in Set 1.
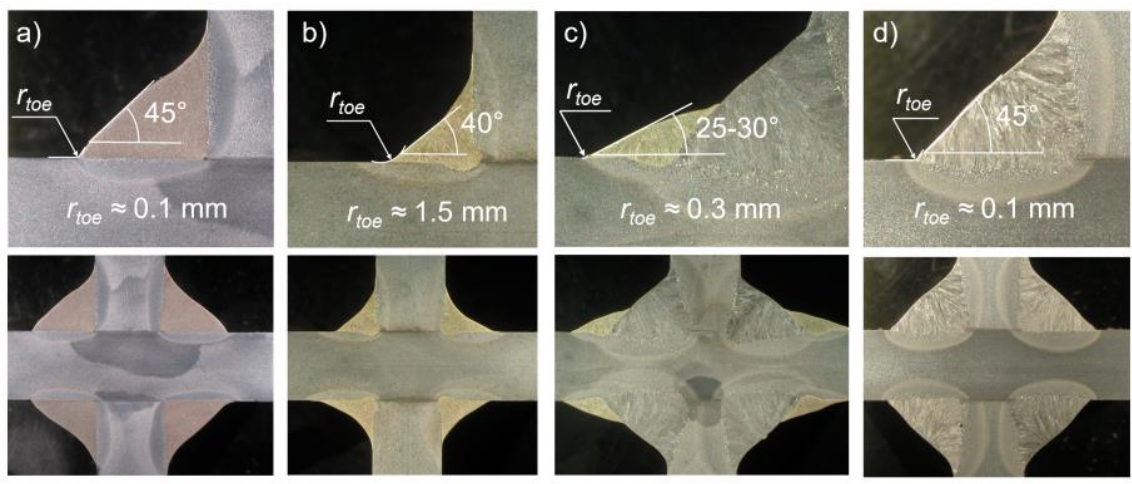

Fig. 8. Typical toe and bead geometries: (a) Set 1, (b) Set 2 and (c) Set 3, and (d) a weld geometry.

During fabrication of the test specimens, it was found that heat conduction must be considered comprehensively when specifying the brazing parameters. For instance, if brazing parameters are established for larger plates and longer brazes, the same parameters are not necessarily optimal for small-scale specimens and shorter brazes. Furthermore, the cleanliness of the joined plates is of importance in brazing in order to ensure acceptable bonding properties.

The FEA revealed that in the NLC X-joints, the SCF at the weld toe decreases by $23 \%$ when a braze alloy with a lower elastic modulus is used for joining the plates, Fig. 6. Comparing the bead geometries of Set 1 and the welded specimens, Fig. 8a and 8d, it can be seen that the bead profile is mainly identical. The mean fatigue strength of the GMA-brazed NLC joints is $22 \%$ higher than that of similar welded specimens. Consequently, a distinct correspondence between the decrease in the SCFs and the improvement in the fatigue strength can be found in Set 1 . Due to the limited number of tested specimens, this paper cannot comprehensively provide a characteristic design $S-N$ curve for GMA-brazed NLC joints. However, the study offers important insights into improvement level in fatigue strength of joints made of UHSS when GMAB is used.

When evaluating the potential of GMAB as a treatment to improve fatigue strength, it must be remembered that the low heat input of GMAB reduces thermal-induced misalignments and distortions causing secondary bending stresses and residual stresses increasing mean stress level. These effects are particularly emphasized when the heat 
input is asymmetric, e.g. in T-joints or one-sided longitudinal gussets. This study focused on the fatigue strength of symmetrically welded and brazed X-joints, in which the misalignments and distortions are clearly lower.

Hardness measurements, Fig. 2b, showed that HAZ-related softening of UHSS cannot be totally avoided when using GMAB, but the depth of the softened zone is quite narrow. This can also be seen in Fig. 8, where in the GMA-welded specimen, the HAZs of the opposite welds almost merge in the middle of the base plate, Fig. $8 \mathrm{c}$-d, while in the GMA-brazed joints, the HAZ occurs only in the vicinity of the plate surfaces, Fig. $8 \mathrm{a}-\mathrm{b}$. The shallow nature of the softened zone contributes to achievement of the high static strength in the NLC joints. Since braze alloys are typically undermatching for UHSSs having yield strength up to $1000 \mathrm{MPa}$, combination joints may be considered particularly in load carrying (LC) joints. Requirements for static and root side fatigue strength can be fulfilled using GMAW (fillet or penetrated welds) with a matching filler material, and the fatigue strength of the weld toe can be improved by using an additional braze bead. The effect of brazing or combined brazing and welding on the static strength capacity of NLC and LC joints should be investigated further in future work.

\section{Conclusions}

In the present paper, the fatigue performance of GMA-brazed NLC joints made of UHSS was investigated experimentally using fatigue tests and numerically using finite element analysis. Based on the results obtained and comparison to previous studies, the following conclusions can be drawn:

- Use of GMAB instead of GMAW in NLC joints can be beneficial in terms of fatigue strength;

- Improvement in fatigue strength can be roughly estimated by observing the decrease in the SCF if other essential parameters, i.e. weld/braze geometry, toe radius, misalignments and residual stresses, are identical;

- Use of GMAB enables attainment of smooth transition from base material to braze bead, which enhances the improvement in fatigue strength significantly, as shown in Set 2, where the fatigue strength improved $75 \%$ with respect to the welded specimens;

- HAZ size and consequently the degree of softening can be significantly diminished when using GMAB with low heat input. Additionally, low heat input reduces residual stresses, which contributes to achievement of high fatigue strength;

- Obtained bead geometries and bonding properties of GMAB are sensitive to the process parameters applied and the cleanliness of the plates and equipment must be ensured.

Acknowledgements The authors wish to thank SSAB, DIMECC Ltd. and the Finnish Funding Agency for Innovation (TEKES) for the funding in the BSA (Breakthrough Steels and Applications) program, and the funding of HRO Design Forum, which together enabled this research work to be completed. 


\section{References}

1. Björk T, Toivonen J, Nykänen T (2012) Capacity of fillet welded joints made of ultra high-strength steel. Weld World 56:71-84. doi: 10.1007/BF03321337

2. Quintino L, Pimenta G, Iordachescu D, et al (2006) MIG brazing of galvanized thin sheet joints for automotive industry. Mater Manuf Process 21:63-73. doi: 10.1081/AMP-200060621

3. Kim Y, Park K, Kwak S (2016) A review of arc brazing process and its application in automotive. Int J Mech Eng Robot Res 5:246-250. doi: 10.18178/ijmerr.5.4.246-250

4. Nikitin A, Schleuss L, Ossenbrink R, Michailov V (2017) Corrosion behavior of brazed zinc-coated structured sheet metal. Int J Corros 1-8. doi: 10.1155/2017/4768505

5. Janota M, Neumann H (2008) Share of spot welding and other joining methods in automotive production. Weld World 52:12-16. doi: 10.1007/BF03266625

6. Murakami T, Nakata K, Tong H, Ushio M (2003) Dissimilar metal joining of aluminum to steel by MIG arc brazing using flux cored wire. ISIJ Int 43:1596-1602. doi: 10.2355/isijinternational.43.1596

7. Bergmann JP, Wilden J, Reich S, Goecke SF (2009) Methods and solutions for joining plates made from different metals using voltaic arc welding. Weld Int 23:895-903. doi: $10.1080 / 09507110902843289$

8. Reisgen U, Angerhausen M, Pipinikas A, et al (2017) The effect of arc brazing process parameters on the microstructure and mechanical properties of high-strength steel HCT780XD using the copper-based filler metal CuAl8. J Mater Process Technol 249:549-558. doi: 10.1016/j.jmatprotec.2017.06.040

9. Varol F, Ferik E, Ozsarac U, Aslanlar S (2013) Influence of current intensity and heat input in Metal Inert Gas-brazed joints of TRIP 800 thin zinc coated steel plates. Mater Des 52:1099-1105. doi: 10.1016/j.matdes.2013.06.054

10. Joseph A, Webb C, Haramia M, Yapp D (2003) Variable polarity (AC) arc weld brazing of galvanized sheet. IIW-document XII-1779-03.

11. Basak S, Pal TK, Shome M (2016) High-cycle fatigue behavior of MIG brazed galvanized DP600 steel sheet joint-effect of process parameters. Int J Adv Manuf Technol 82:1197-1211. doi: 10.1007/s00170-015-7451-1

12. Sharma A, Lee SJ, Choi DY, Jung JP (2017) Effect of brazing current and speed on the bead characteristics, microstructure, and mechanical properties of the arc brazed galvanized steel sheets. J Mater Process Technol 249:212-220. doi: 10.1016/j.jmatprotec.2017.05.026

13. Lepistö JS, Marquis GB (2004) MIG Brazing as a Means of Fatigue Life Improvement. Weld World 48:28-40. doi: 10.1007/BF03263399

14. Gericke A, Glienke R, Henkel K-M, et al (2017) Reduction of the notch effect of nonloaded attachments on steel structures through arc brazing. 70th IIW Annu. Assem. Int. Conf. - Comm. XIII - WG2

15. EN 1011-1 (2009) Welding - Recommendations for welding of metallic materials - Part 1: General quidance for arc welding.

16. Hobbacher A (2016) Recommendations for Fatigue Design of Welded Joints and Components, 2nd ed. Springer International Publishing, Cham

17. Radaj D, Sonsino CM, Fricke W (2006) Fatigue Assessment of Welded Joints by Local 
Approaches, 2nd editio. Woodhead Publishing, Cambridge

18. Sonsino CM, Fricke W, De Bruyne F, et al (2012) Notch stress concepts for the fatigue assessment of welded joints - Background and applications. Int J Fatigue 34:2-16. doi: 10.1016/j.ijfatigue.2010.04.011

19. Fricke W (2012) IIW Recommendations for the Fatigue Assessment of Welded Structures by Notch Stress Analysis. Woodhead Publishing

20. Baumgartner J, Bruder T (2013) An efficient meshing approach for the calculation of notch stresses. Weld World 57:137-145. doi: 10.1007/s40194-012-0005-3

21. Skriko T, Björk T, Nykänen T (2014) Effects of weaving technique on the fatigue strength of transverse loaded fillet welds made of ultra-high-strength steel. Weld World 58:377-387. doi: 10.1007/s40194-014-0123-1

22. Ahola A, Nykänen T, Björk T (2017) Effect of loading type on the fatigue strength of asymmetric and symmetric transverse non-load carrying attachments. Fatigue Fract Eng Mater Struct 40:670-682. doi: 10.1111/ffe.12531

23. Karppi R, Leiviskä P, Laitinen R (2008) Developments in MAG-welding for ultra high strength steel; Optim 960 QC. In: Int. Symbosium "From Weld. Fract. to Pipeline Technol. pp 1-20 